Neurobiology

\section{More nerve growth factors?}

\author{
from Joshua R. Sanes
}

THE discovery of nerve growth factor (NGF) by Levi-Montalcini and Hamburger ${ }^{1}$ was the first major step in the molecular analysis of neural development, and remains the most influential achievement in this rapidly growing field. This soluble protein is required for the survival of sympathetic and sensory neurones in vivo and in vitro: in culture, it also promotes neuronal differentiation and chemotactically directs growing axons. NGF has been purified and sequenced, its genes are being cloned and mapped, and studies of its mechanism of action are underway. The current dogma is that NGF is produced by peripheral target tissues, picked up by nearby axons, and transported back to neuronal somata. Competition for limited supplies of NGF may determine which neurones live and which die during embryogenesis. In addition, NGF may act locally in the periphery as a stimulant and attractant, to regulate the size and shape of an axon's terminal field. Finally, NGF may be required for neuronal maintenance in adulthood, with loss of its supply - after axon injury, for example signalling the neurone that adjustment or repair is required (reviewed in refs $2-4$ ).

The early realization that only a few types of neurone are sensitive to NGF led to speculation that NGF was but one of a family of trophic agents ${ }^{5}$. If each of several cell types turned out to secrete limited amounts of a factor that supported its own innervation, retrograde trophic control would provide a general means to match the sizes of pre- and post-synaptic populations. Furthermore, a system of selective trophic sustenance might play some limited part in synaptic specificity: that is, in determining which cells or connections, as well as how many cells or connections, form or survive. Among the first steps in the hunt for other trophic factors have been the demonstration that extracts of appropriate targets support parasympathetic neurones in vitro $o^{6,7}$, and the purification of a protein from brain that allows survival of some cultured neurones that do not respond to $\mathrm{NGF}^{8}$.

From a cell biological point of view, the most useful new factor to obtain would be one that supports somatic motor neurones - a motor neurone growth factor (MNGF). The skeletal neuromuscular junction is the best studied of all synapses and would be a good system for studying factor uptake and action. Fortunately, there is reason to suspect that a MNGF exists, in that several aspects of neuromuscular synapse formation seem to reflect control by muscle-derived factors. In the embryo, spinal motoneurones (like many other neuronal types) are normally produced in excess; $30-50$ per cent of them degenerate before the animal is born. Peripheral control of this process is indicated by the observation that the naturally occuring cell death can be increased by extirpation of the appropriate target, while neurones that would otherwise die can be rescued by grafting on extra target tissue. In the neonate, several axons innervate each skeletal muscle fibre. Excess inputs are withdrawn until each fibre receives a single input, and it has been proposed that even after a neurone's survival has been assured, its individual axonal branches continue to fight for the limited support that each muscle fibre can furnish. In the adult, partial denervation of a muscle induces the undamaged axons to sprout and reinnervate the denervated muscle fibres. Again, several aspects of the sprouting phenomenon suggest that it represents an axonal response to soluble factors released by denervated fibres. Thus, neuromuscular connectivity could be regulated in part by the supply and/or effectiveness of MNGF(s) throughout the life of an animal (reviewed in refs 9-12).

How, in turn, might the supply of such growth factors be regulated? Again, previous studies of muscle suggest a candidate: electrical (or contractile) activity. Paralysis of muscle rescues embryonic motoneurones destined to die, slows elimination of polyneuronal innervation in neonates and evokes sprouting in adults; conversely, chronic stimulation speeds synapse elimination and prevents sprouting ${ }^{8-11}$. Since many aspects of muscle metabolism are already known to be activity-dependent, it is tempting to suppose that denervated or inactive muscles secrete more MNGF than innervated, active muscles. Neurones could thus control and be controlled by their supply of factor, establishing a feedback loop.

Aware of these and other issues, many groups have begun to search for a MNGF. The most common approach has been to culture motor (or spinal cord) neurones in a minimal medium, and to assess the effects of adding muscle extracts or musclesecreted material. Supplements have been found that increase levels of neurone survival, neurite extension, or transmitter synthetic capacity ${ }^{13-21}$. As one might have hoped, extracts are more active when made from neonatal or denervated muscle than from innervated adult muscle ${ }^{18-21}$. Early attempts at fractionation suggest that the extracts may contain several active factors, which differ in their modes of action (some seem to act in solution, others after first attaching to the substratum) and effects (for example, activities that promote neuronal survival and differentiation can be separated from each other). However, purification of the factor(s) has not yet been achieved.

So far, all attempts to identify a MNGF have relied on neurones in culture as bioassay. Now Gurney ${ }^{22}$ reports, in this issue of Nature (p.546), results of an alternative immunological approach. He used a series of antisera (originally prepared at the MRC, London) to material secreted by organ-cultured denervated muscle. To carry out an assay he injected the sera into paralysed but innervated mouse muscles and looked for suppression of the sprouting that would normally occur. Gurney's paper contains three intriguing results. First, several antisera partially prevented sprouting in vivo. Second, each blocking serum recognized a 56,000 -molecular-weight (56K) protein on immunoblots of muscle-secreted material. Third, and perhaps most astonishing, sera from patients with amyotrophic lateral sclerosis (ALS) not only blocked sprouting when injected but also recognized a $56 \mathrm{~K}$ antigen on immunoblots. ALS is a disease in which many spinal motoneurones die and surviving motoneurones sprout poorly. Thus, the properties of ALS sera both provide a possible clue to the aetiology of this fatal disease and lend further support to the notion that a $56 \mathrm{~K}$ protein may regulate sprouting.

Is the $56 \mathrm{~K}$ antigen a MNGF? A promising preliminary result is that the antigen is present in an incompletely purified fraction that promotes neurite extension and survival of cultured spinal cord cells (ref. 22 and personal communication). If further work proceeds well, the idea that neurones of different types and of different ages are maintained in a trophic equilibrium will be open to new and exacting tests.

Joshua $R$. Sanes is in the Department of Physiology and Biophysics, Washington University Medical Center, St Louis, Missouri 63110.

1.cvi-Montalcini, R. \& Hamburger, V. J. exp. Zool. 116 321 (1951).

Thoenen, H. \& Barde, Y.-A. Physiol. Rev, 60, 1284 (1980)

3. Yanker, B.A.\& Shooter, E.M. A. Rev. Biochem. 51, 845 (1982).

4. Bradshaw, R. A Nature 303, 751 (1983).

5. Purves, D. in Function and Formation of Neural Systems (ed. Stent, G.S.) 21 (Dahlem Konferenzen, Berlin, 1977)

Manthorpe, M. et al. J. Neurochem, 34, 69 (1980).

Nishi, R. \& Berg, D.K. J. Neurosci. 9. 505 (1981).

8. Bardc, Y.-A., Edgar, D. \& Thoenen, H. EMBO J. 1549 (1982).

Hamburger, V. \& (ippenheim, K. U. Neurosci. Comment. 1. 39 (1982)

0. Grinnell, A.D. \& Harrera, A.A. Prog. Neurobiol. 17, 203 (1981).

1. Brown, M.C., Holland, R.1.. \& Hophins, U. (i. Rev Neurosci. 4, 17 (1981).

. Slach, J.K. \& Pochett, S. Muscle Nerve 6, 243 (1983)

Dribin, L.B. \& Barrelt, J.N. Devl Biol. 74, $184(1980)$

14. Henderson. C.E., Buchet, M. \& Changeux, J.-P. Proc mein Acad Sci U.S. A. 78, 2625 (1981)

15. Bennetl, M.K. L ai, K. \& Nurcombe, V. Brain Res. 190,537 (1980).

6. (iiller, E.I.., Neale, J.H., Bulloch, P.N., Schricr, B.K. \& Nelison, B. J. Cell Biol. 74, 16 (1977)

Tanaha, H. \& ( bata, K. Develop. Brain Res. 4, 313 (1982).

. Smith, K.Ci. \& Appol, S.H. Science 219, 1079 (1983).

19. Hendersen, C.E... Buchel, M. \& Changcux, J.-P. Nature 302, $6(09)(1983)$

2). Slach, J.K. \& Pochet1, S. Brain Res. 247. 138 (1982)

Nurcombe, V. el al. Brain Res. 291, 19 (1984).

(iurnis. Mit. Nature 307. 546 (1984). 